\title{
Serving those who served us Resources for active duty soldiers and veterans
}

$\mathbf{T}$

he statistics are staggering in many areas for U.S. active duty military personnel and veterans. As of September 2011, there were $1,468,364$ active duty military personnel. ${ }^{1}$ In 2010 , there were 21.8 million veterans in the United States. ${ }^{2}$ Accurate statistics on homeless veterans are difficult to substantiate, but the Veterans Affairs (VA) secretary believes the 2012 statistics show the number to be less than 60,000. ${ }^{3}$ According to the New York Times, suicide rates of military personnel and combat veterans have risen sharply since 2005. ${ }^{4}$ Substance abuse in the form of prescription drug abuse doubled among U.S. military personnel from 2002 to 2005 and almost tripled between 2005 and 2008, according to the National Institute on Drug Abuse. ${ }^{5}$

Numerous veterans face an uncertain future; dealing with physical, emotional, and mental health issues. Current soldiers may return from battle with emotional and physical concerns. Female soldiers and veterans may be dealing with the scars of sexual assault or harassment. The statistics should compel us to do everything we can to provide assistance to active military and retired personnel. This article details some of the resources available; librarians must be ready to assist active duty members, veterans, their families, and professional associates in locating resources to help members of the U.S. military, past and present.

\section{General resources}

- The United States Department of Veterans Affairs. The veterans organization provides information on a multitude of subjects, including Services (new to VA?, benefits and services, health and well-being, and burial and benefits), Business (starting and doing business with the VA), Media (press releases, special events), and Locations (clinics, hospitals, cemeteries, and benefits offices). The News and Hot Topics sections on the homepage provide pertinent information to the viewer. The Special Programs section provides links to information on homeless vets, service benefits, programs for female vets, adaptive sports program, and information for surviving spouses and dependents. An excellent starting point for services available for active duty and retired military. Access: http://www.va.gov.

- The United States Department of Veterans Affairs: Center for Women Veterans. The VA Department has some separate areas focused on specific issues facing women. One of the Web sites is dedicated to a variety of topics for women: health care, benefits (education, benefits, compensation, etc.), and Stories of Service. A Fact Sheet provides data on the mission of the organization, legislation, activities, and obtaining assistance. Access: http://www.va.gov/womenvet/.

- Women Veterans Health Care. Another concentrated area provided for

Karen Evans is reference and instruction librarian at Indiana State University's Cunningham Memorial Library, e-mail: karen.evans@indstate.edu

(0) 2012 Karen Evans 
women veterans, focusing on health care. Areas covered include Health Care Services (primary, specialty, telephone, and special groups), FAQ's, Wellness and Healthy Living, Publications, and Celebration Posters. Videos and More Resources (sexual military trauma, homelessness, and crisis line) add to the extensive information available on this site. Access: http://www.womenshealth.va.gov/.

- Veterans History Project. The National Archives and Records Administration (NARA)

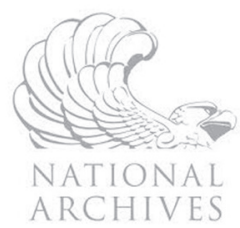
is the record keeper for the United States. Their site provides information on locating military service records (including pre-World War I records), using military records to research, and replacing lost medals and awards. Browse World War II leads to a wealth of resources, including African Americans during World War II, captured Nazi recordings (list of speeches and broadcasts), World War II sound recordings from 1937 to 1945, and much more. Information is available on specific wars, from the Revolutionary War to Vietnam. The Veterans Day events site provides a link to a display of posters for SPARS and WAVES, a glimpse into the past on women who served in the military. Access: http://www.archives.gov/.

\section{(s) VETERANS U HISTORY PROJECT}

\section{Brain injury and post traumatic stress disorder (PTSD)}

- Defense Centers of Excellence: For Psychological Health and Traumatic Brain Injury. Established in 2007, the centers' vision is to become "a trusted source and advocate for psychological health and traumatic brain injury" for the Department of Defense. Information is provided for Warriors, Families, News Media, and Health Professionals. Warrior resources include suicide prevention, traumatic brain injury, pre- and post-deployment, locating health care, guard and reserve information, and the Real Warriors Campaign. Family links include adjusting to change, taking care of yourself, supporting your service member, and helping children cope. Media resources include press releases, information sheets, and DCoE/DoD sports

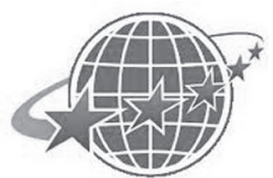

DEFENSE CENTERS OF EXCELLENCE

For Psychological Health \& Traumatic Brain Injury collaborations. The Health Professionals section includes TBI information, psychological health resources, treatment options, and tips for civilian health care professionals. Telephone (24/7), e-mail, and live chat assistance is available for those in crisis. Additional resources include Resources (after deployment, TBI, suicide prevention), Links (warriors, families, health professionals), podcasts, and videos. Access: http://www.dcoe.health.mil/ default.aspx.

- Defense and Veterans Brain Injury Center (DVBIC). DVBIC is part of the U.S. military, and the "traumatic brain injury operational component of the Defense Centers of Excellence for Psychological Health and Traumatic Brain Injury (TBI).” This site provides a wealth of information for the service members, veterans, family members, and the medical community. A wide variety of resources are included in the Educational Materials section; it is one of the most valuable areas in the site for information. Among the other resources are Fact Sheets, Signs and Symptoms, Taking Care of Yourself While Caring For Others, Addressing Family Needs, and Talking With Children about TBI. Research on TBI and DVBIC locations provide additional resources for users. Access: http://www.dvbic.org/.

- Make the Connection: Shared Experiences and Support for Veterans. Make the Connection is a resource that allows veterans to relate their experiences and find a variety of support services. Users are able to customize the site (sex, date, branch of service, etc.) and receive sources pertinent to their experiences. Information is available for veterans, family and friends, clinicians, 
and others. Stories of Connection (retirement and aging, family and relationships), Signs and Symptoms (nightmares, substance abuse), Conditions (PTSD, depression), and Resources and Support (treatment and recovery, self-help) are also available. Access: http://maketheconnection.net/.

- United States Department of Veterans Affairs: National Center for PTSD. Site provides information on PTSD for the public (family, friends, veterans) and professionals (researchers, providers). These two sections provide information on a variety of topics, including treatment programs, returning from the war zone, clinician guide, and assessment of trauma and PTSD. A section entitled About Face features veterans discussing how treatment helped them cope with PTSD. There is a division on women and PTSD, including rape, sexual assault, and traumatic stress. Access: http://www.ptsd.va.gov/.

\section{Deployment, homecoming, and family life}

- American Academy of Child \& Adolescent Psychiatry: Coming Home: Adjustments for Military Families. Provides information on helping families adjust to life after deployment. Sections include the returning family member, the adult that stayed home, children, and the family unit. A link provides additional information on families in the military, including signs of stress in children (symptoms according to age, from birth to 18 years old), and a section on easing family stress when a parent is deployed. Access: http://www.aacap.org/cs /root/facts_for_families/coming_home _adjustments_for_military_families.

- Commander Navy Installation Center: Fleet and Family Support Program. Provides a wealth of resources for military families. Programs include deployment readiness, personal finances, transition and relocation assistance, new parent support, life skills (anger and conflict management, new spouse orientation, suicide prevention, and stress management). Specific programs are available for families, youth, and children.
This is a source geared toward the family and ensuring families have a successful and productive military life. Access: http://www. cnic.navy.mil/CNIC_HQ_Site/WhoWeAre /index.htm.

- National Military Family Association: Deployment. Deployment is the theme of this Web site. Links including preparing and managing for a successful deployment, legal and financial issues, talking with kids, child care, and coping with emergencies. Return issues are covered with links to Reunion and Back Home. The Reunion page includes links to resources for particular military divisions. Additional resources include mental health care, spouse education, and supporting children during deployment. Links to military and civilian support groups are also listed. Access: http://www.militaryfamily.org /get-info/deployment/.

\section{Education}

- VA: Welcome to the G.I. Bill. The site provides information resources available through the G.I. Bill, applying for benefits, the Post G.I. Bill and other programs, benefit and education resources, counseling for vocational and educational issues, FAQ's, and contact information for assistance. A section on Choosing a School provides information on things to consider before making career or educational decisions. Videos tell the story of veterans from different branches of service. Access: http://gibill.va.gov/.

- Real Warriors: Five Resources for Returning to School. Provides five steps for those considering higher education. Among the five steps is Tips from Student Veterans, including a link to a Military to College Guide. The guide provides information on transitioning to a college or university, educational and employment resources, VA forms, and a veterans' information checklist to make the transition easier. Access: http:// www.realwarriors.net/veterans/treatment /studentveterans.php.

- United States Department of Education: Military Families and Veterans. One of the best sections of this site is the 
Resources section, containing a multitude of links for users. Information is available on Readmission Requirements for Service Members, school liaison programs with the Army, Marines, and Navy, and Support for Military Families. Other areas include Funding, Policy, and Research information. Access: http:// www.ed.gov/veterans-and-military-families

\section{Employment}

- U.S. Department of Labor: Veterans' Employment and Training Service (VETS). The VETS program has a collection of sources to assist veterans, active duty military, and employers in locating and matching military personnel with employment. Divisions are clearly labeled for Service Members, Family and Veterans, Employers, Service Providers, and Updates. Information is provided on grants for job training, hiring fairs, grants for homeless vets, and a compensation and benefits handbook for ill, wounded, and injured service members. Access: http://www. dol.gov/vets/.

- U.S. Small Business Administration: Office of Veterans Business Development. SBA has a diverse assortment of programs available to assist veterans, reserve members of the military, family, and survivors with small businesses. The SBA provides information on starting a business, competing for grants, and hiring employees. A list of programs (Operation Boots to Business, Women Veterans Igniting the Spirit of Entrepreneurship, and Operation Endure and Grow) is available. Resources include a Balancing Business and Deployment Guide and Getting Veterans Back to Business. Access: http:// www.sba.gov/about-offices-content/1/2985.

- Turbo Tap. Org: Employment Assistance. This Department of Defense site includes a Career Decision Toolkit incorporating many components involved in developing a career, including Career Exploration, Financial Planning, Job Search, Effective Resumes and Cover Letters, and Interviewing Skills. Additional material is available on transition, from Relocation Assistance to Leaving the Service. The full transition services are avail- able after separation from the military. Access: http://www.turbotap.org/register.tpp.

\section{Substance abuse and suicide}

- National Alliance on Mental Illness (NAMI): Veterans and Military Resource Center. This easy-to-use site delivers material on a diverse list of issues military personnel can face. PTSD, TBI, homelessness, suicide, and mental illness. Specific sections are available for families, women, active duty, and those from culturally diverse populations. Access: http://www.nami.org/Template. cfm?Section=Veterans_Resources\&Template=/ ContentManagement/ContentDisplay. cfm\&ContentID=53242\&lstid $=877$.

- National Alliance on Mental Illness (NAMI): Veterans and Suicide. NAMI provides a variety of links providing assistance to active duty and veterans, including branchspecific resources. Information is also available on programs for wounded and real warriors, returning veterans, and the vet2vet crisis line. Branch specific resources on suicide are also available. Access: http://www.nami. org/Content/NavigationMenu/Find_Support /Veterans_Resources/Veterans_and_Suicide /Veterans_and_Suicide.htm.

- Veterans Crisis Line. Launched in 2007, the Veterans Crisis Line provides professional assistance to veterans, family, and friends 24 hours a day, 365 days a year. The crisis line can be contacted by telephone, live chat, or text. Specific help is available for veterans, current duty, and families and friends of military personnel. A Network of Support allows the Crisis Line to provide contact information for PTSD, TBI, military sexual trauma, and family and relationship issues. This site provides numerous ways for someone to connect with professional responders for help with a variety of issues. Access: http://veteranscrisisline.net/.

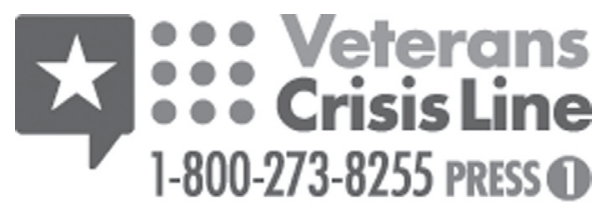

(continues on page 480) 
search collections. It could be scaled to larger libraries, but the focus would have to be very narrow so as not to overwhelm students by the sheer volume of material. The assessment also requires library administration to seriously consider student recommendations to the collection based on sound historiographical analysis.

\section{Conclusion}

This faculty/librarian collaboration has allowed librarians to meet more students in a classroom setting and interact with them about a host of issues related to the wider world of information. For example, many students are initially very surprised by the amount of money the library pays for electronic and print materials. These sessions also allow librarians to better understand how students view the changing composition of the collection as the library makes major investments in e-book and e-reference resources. It has also sparked interest among other subject librarians to suggest a similar type of assessment in their liaison areas. Finally, being able to give students a direct and profession-based role in building the collections has provided them with a better understanding of the usefulness of an annotated bibliography while connecting them to the library as place.

As one student reflected, "I plan to build annotated bibliographies not only for my finished work but also to aid me in the process of research. Having a bibliography with a short description to go back to would be beneficial if I would need to flesh out certain arguments or expand on specific examples. I really enjoyed this assignment. It renewed my love for books and libraries."

\section{Notes}

1. Stephanie S. Brasley, "Effective Librarian and Discipline Faculty Collaboration Models for Integrating Information Literacy into the Fabric of an Academic Institution," New Directions for Teaching and Learning no. 114 (2008): 71-88. Accessed March 26, 2012. http://0-search.ebscohost.com. topcat.switchinc.org/login.aspx?direct=tru $\mathrm{e} \& \mathrm{db}=\mathrm{aph} \& \mathrm{AN}=32750177 \&$ site $=$ ehost-live . Trudi E. Jacobson and Thomas P. Mackey, Information Literacy Collaborations that Work (New York: Neal-Shuman Publishers, 2007).

2. Alverno College, "Ability-Based Learning Program," 2005.

3. Alverno College, "Alverno College Library Student Survey," 2010. The complete survey results can be obtained by sending an e-mail to larry.duerr@alverno.edu.

4. A copy of the assessment can be obtained by sending an e-mail to larry.duerr@ alverno.edu.

5. Alverno College, "Advanced Outcomes in the Major Area, Discipline: History," 2011. n

("Serving those who served us," cont. from page 473)

\section{Notes}

1. "Infoplease: Active Duty Military Personnel, 1940-2011," retrieved from www. infoplease.com/ipa/A0004598.html/.

2. "Infoplease: American Veterans by the Numbers," retrieved from www.infoplease. $\mathrm{com} / \mathrm{spot} /$ veteranscensus1.html.

3. Leo Shane III "VA figures show steep decline in number of homeless veterans," Stars and Stripes, retrieved from www.stripes.com/news/va-figuresshow-steep-decline-in-number-of-homelessveterans-1.179016.
4. Timothy Williams, "Suicides outpacing war deaths for troops," New York Times, retrieved from http://www.nytimes.com/2012/06/09 /us/suicides-eclipse-war-deaths-for-us-troops. html/.

5. National Institute on Drug Abuse, "Topics in brief: Substance abuse among the military, veterans, and their families (April 2011), retrieved from www.drugabuse.gov /publications/topics-in-brief/substance -abuse-among-military-veterans-their -families. $n$ 